https://doi.org/10.15407/dopovidi2020.10.022

УДК 517.58/.5892

\author{
A.N. Khimich ${ }^{1}$, I.T. Selezov ${ }^{2}$, V.A. Sydoruk ${ }^{1}$ \\ ${ }^{1}$ V.M. Glushkov Institute of Cybernetics of the NAS of Ukraine, Kyiv \\ 2 Institute of Hydromechanics of the NAS of Ukraine, Kyiv \\ E-mail: khimich505@gmail.com, igor.selezov@gmail.com,wolodymyr.sydoruk@gmail.com
}

\title{
Simulation of elastic wave diffraction by a sphere in semibounded region
}

Presented by Corresponding Member of the NAS of Ukraine A.N. Khimich

The problem of scattering of plane elastic waves by a rigid sphere located near a plane rigid boundary is considered, which leads to the generation of multiply re-reflected dilatation and shear waves. The formulation of the problem is given when slippage conditions are specified on a flat boundary (equality of tangential stresses to zero). The problem is reduced to the definition of scalar functions. General solutions are written down, and approximate solutions are constructed for the field in the far zone characterized by the fact that the distance from the plane boundary to the obstacle is much greater than the radius of the sphere. In addition, the Rayleigh approximation is used, when the wave number is much lesser than the radius of the sphere. The method of images is used to construct multiply reflected waves. Approximate formulas are given for the field in the far zone and in the case of the long-wave Rayleigh approximation. The calculations of scattered wave fields, presented in the form of scattering diagrams, are carried out, from which a strongly oscillating wave field can be seen.

Keywords: wave diffraction, elastic waves, sphere, semibounded region, image method, oscillating field, wavelength.

Most materials of microelectronic devices, including the computer ones, can contain foreign inclusions, which can lead to strong oscillations of the wave field due to the occurrence of reflected waves. Rigid inclusions can be found in many different materials, as well as in human biological tissues. In these cases, a complex wave field of re-reflected waves occurs, which leads to oscillations. This problem is modeled here as the problem of wave diffraction on a rigid spherical inclusion near a flat rigid boundary, which generalizes the previously considered problems (Selezov et al., 2018) [1], (Selezov, 1993) [2].

Consider a spherical coordinate system $r, \theta, \varphi$ (the radial, zenithal and azimuthal coordinates), which corresponds to a rectangular Cartesian coordinate system $x, y, z$. The $O y$ axis is perpendicular to the flat boundary with the origin at the center of an absolutely rigid spherical inclusion (scatterer) and is directed from infinity to the flat boundary.

Ци ту вання: Khimich A.N., Selezov I.T., Sydoruk V.A. Simulation of elastic wave diffraction by a sphere in semibounded region. Допов. Наи. акад. наук Укр. 2020. № 10. С. 22-27. https://doi.org/10.15407/dopovidi 2020.10 .022 
When plane waves run from infinity (plane waves propagate along the $O y$ axis), a diffracted field of repeatedly re-reflected waves appears in the system.

A plane wave of displacements propagates from infinity along the $\mathrm{Oy}$ axis

$$
u_{y}(0, y, 0, t)=u_{0} e^{i(p y+\omega t)} .
$$

The motion of an elastic medium is described by the equations

$$
\left(\nabla^{2}-\frac{1}{c_{e}^{2}} \frac{\partial^{2}}{\partial t^{2}}\right) \psi=0, \quad\left(\nabla^{2}-\frac{1}{c_{s}^{2}} \frac{\partial^{2}}{\partial t^{2}}\right) \vec{a}=0,
$$

and the displacement vector is determined by the formula

$$
\vec{u}=\vec{\nabla} \psi+\vec{\nabla} \times \vec{a}, \quad \vec{\nabla} \cdot \vec{a}=0 .
$$

The boundary conditions on the sphere and on the flat boundary have the form

$$
\left.\left.u_{r=a}\right|_{r=0,} u_{\theta}\right|_{r=a}=0,\left.u_{y}\right|_{y=-h}=0,\left.\quad \sigma_{x y}\right|_{y=-h}=0 .
$$

Conditions (4) mean that, on the surface of the sphere $r=a$, the displacement vector is zero. On the plane boundary $y=-h$, its normal component and tangent stress are zero (slippage). The desired functions must also meet the Sommerfeld radiation conditions.

When introducing dimensionless values, the characteristic values are taken as: length [m] - radius of the sphere $a$, time [s] - 1/ $\omega$, kilogram-mass [kg] - Young modulus.

The equation for the incoming wave determines, in accordance with (2), the potential $\psi$ corresponding to dilation waves

$$
\left(\frac{\partial^{2}}{\partial y^{2}}-\frac{1}{c_{e}^{2}} \frac{\partial^{2}}{\partial t^{2}}\right) \psi(y, t)=0
$$

Equations (2) follow from the equations of elastodynamics

$$
G \nabla^{2} \vec{u}+(\lambda+G) \vec{\nabla}(\vec{\nabla} \cdot \vec{u})=\rho \frac{\partial^{2} \vec{u}}{\partial t^{2}}
$$

with the use of a well-known formula $\vec{\nabla} \times \vec{\nabla} \times \vec{a}=\vec{\nabla}(\vec{\nabla} \cdot \vec{a})-\nabla^{2} \vec{a}$. As a result, the definition of the operator $\vec{\nabla} \times \vec{a}$ in (3) is reduced to the definition of the operator $\nabla^{2} \vec{a}$ (Morse \& Feshbach) [3]. In the case of axial symmetry $\frac{\partial(\bullet)}{\partial \varphi}=0$, we get

$$
\begin{aligned}
& \nabla^{2} \vec{a}=\vec{e}_{r}\left[\nabla^{2} a_{r}-\frac{2}{r^{2}} a_{r}-\frac{2}{r^{2} \sin \theta} \frac{\partial}{\partial \theta}\left(\sin \theta a_{\theta}\right)\right]+ \\
& +\vec{e}_{\theta}\left[\nabla^{2} a_{\theta}-\frac{a_{\theta}}{r^{2} \sin ^{2} \theta}+\frac{2}{r^{2}} \frac{\partial a_{r}}{\partial \theta}\right]+\vec{e}_{\varphi}\left[\nabla^{2} a_{\varphi}-\frac{a_{\varphi}}{r^{2} \sin ^{2} \theta}\right] .
\end{aligned}
$$


The third term in expression (6) is also zero, since $a_{\varphi}=0$. The components $a_{\varphi}$ are the projections of the vector $\vec{a}$ onto the coordinate line $\varphi$ and are equal to zero in the case of axial symmetry. By analogy with the construction of the equation for $\psi(5)$ we can introduce a scalar function $\xi(r, \theta)$ with normalization $u_{0}$, which depends on two arguments, i.e. we obtain the scalar wave equation for the scalar function $\xi(r, \theta)$

$$
\left(\nabla^{2}-\frac{1}{c_{s}^{2}} \frac{\partial^{2}}{\partial t^{2}}\right) \xi=0
$$

From it, after the separation of variables, the Legendre equation and the Bessel equation for spherical functions follow.

Solutions to the problem of elastic wave diffraction by a sphere (Seismic, 2016) [ 4 ] in an infinite domain for functions $\psi$ and $\xi$ are written as

$$
\psi=\sum_{m=0}^{\infty}\left[f_{m} j_{m}(p r)+a_{m} h_{m}^{(2)}(p r)\right] \quad P_{m}(\cos \theta), \quad \xi=\sum_{m=0}^{\infty} b_{m} h_{m}^{(2)}(q r) \frac{\partial}{\partial \theta} P_{m}(\cos \theta),
$$

Where $f_{m}=-(2 m+1) \quad u_{0} p^{-1} i^{-(m+1)}, j_{m}(p r)$ and $h_{m}^{(2)}(p r)$ are spherical Bessel and Hankel functions. For example, $j_{m}(\zeta)=J_{m+\frac{1}{2}}(\zeta) \sqrt{\frac{\pi \zeta}{2}}$.

From the first two boundary conditions (4) using (7), we obtain the coefficients $a_{m}$ and $b_{m}$ :

$$
\begin{aligned}
& a_{m}=f_{m} \Delta_{m}^{-1}\left\{m(m+1) j_{m}(p a) h_{m}(q a)-p a j_{m}^{\prime}(p a)\left[h_{m}(q a)+q a h_{m}^{\prime}(q a)\right]\right\}, \\
& b_{m}=f_{m} \Delta_{m}^{-1} p a\left\{h_{m}(p a) j_{m}^{\prime}(p a)-h_{m}^{\prime}(p a) j_{m}(p a)\right\}, \\
& \Delta_{m}=p a h_{m}^{\prime}(p a)\left[h_{m}(q a)+q a h_{m}^{\prime}(q a)\right]-m(m+1) h_{m}(p a) h_{m}(q a) .
\end{aligned}
$$

We find approximate solutions for the field in the far zone $\frac{r}{a}>>1$ by representing the Hankel functions by their asymptotic expansions at large $r / a$,

$$
u_{r} \cong \sum_{m=0}^{\infty} a_{m} i^{m} \frac{1}{r} e^{-i p r} P_{m}(\cos \theta), u_{\theta} \cong-\sum_{m=0}^{\infty} b_{m} i^{m} \frac{1}{r} e^{-i q r} \frac{\partial}{\partial \theta} P_{m}(\cos \theta) .
$$

In the Rayleigh approximation, the quantities $p a$ and $q a$ satisfy the inequalities $p a, q a \ll 1$. In this case, it can be established from (8) and (9) that the dominant coefficients are

$$
a_{1} \cong i \quad 3 a\left[1+2\left(\frac{q}{p}\right)^{2}\right]^{-1}, \quad b_{1} \cong i \quad 3 a\left[1+2\left(\frac{q}{p}\right)^{2}\right]^{-1}\left(\frac{q}{p}\right)^{2}
$$

To construct solutions in a semiinfinite region, we use the image method (Jackson, 1962) [5]. A solution satisfying the second two boundary conditions (4) in each $k$-th approximation is represented in the form 


$$
\vec{u}\left(r, \theta, r^{*}, \theta^{*}\right)=\sum_{k=1}^{\infty}\left[\vec{u}_{k}(r, \theta)+\vec{u}_{k}^{*}\left(r^{*}, \theta^{*}\right)\right],
$$

where the summary components of displacements for the scattered field of multiplicity $k$ have the form

$$
\begin{aligned}
& \left(\vec{u}_{k}+\vec{u}_{k}^{*}\right)_{r}=U_{r k}=u_{r k}-u_{r k}^{*} \cos \left(\theta+\theta^{*}\right)+u_{\theta k}^{*} \sin \left(\theta+\theta^{*}\right), \\
& U_{\theta k}=u_{\theta k}+u_{\theta k}^{*} \cos \left(\theta+\theta^{*}\right)-u_{r k}^{*} \sin \left(\theta+\theta^{*}\right) .
\end{aligned}
$$

Difference in distances from real and imaginary obstacles to a certain point $r, \theta$ and the time difference of arrivals of $P$ - and $S$-waves in the first approximation are taken into account by the formulas

$$
\begin{aligned}
& \exp \left(-i \alpha_{j}\right)=\left(\cos \eta_{j}-i \sin \eta_{j}\right) \exp (-i p r), \alpha_{0}=q r, \alpha_{1}=p r^{*}, \alpha_{2}=q r^{*}, \\
& \eta_{0}=\operatorname{pr}\left(\frac{q}{P}-1\right), \eta_{1}=\eta_{p}=\operatorname{pr}(\eta-1), \eta_{2}=\eta_{q}=p r\left(\frac{q}{p} \eta-1\right)
\end{aligned}
$$

Formulas (13) follow from the geometric relations obtained above for the main and mirror obstacles.

By formulas (10) (13), after a series of transformations for a singly scattered field, we find

$$
\begin{aligned}
& U_{r 1} \cong-\cos \theta+\left(\frac{2 h}{r} \cos \theta-1\right)\left(\frac{2 h}{r}-\cos \theta\right)\left(\cos \eta_{p}-i \sin \eta_{p}\right) \eta^{-3}+ \\
& +\left(\frac{q}{p}\right)^{2}\left(\cos \eta_{q}-i \sin \eta_{q}\right) \frac{2 h}{r} \eta^{-3} \sin ^{2} \theta \\
& U_{\theta 1} \cong\left[-\left(\frac{q}{p}\right)^{2}\left(\cos \eta_{q}-i \sin \eta_{q}\right)-\left(\frac{2 h}{r} \cos \theta-1\right)\left(\cos \eta_{q}-i \sin \eta_{q}\right) \eta^{-3}\left(\frac{q}{p}\right)^{2}-\right. \\
& \left.-\left(\frac{2 h}{r}-\cos \theta\right)\left(\cos \eta_{p}-i \sin \eta_{p}\right) \frac{2 h}{r} \eta^{-3}\right] \sin \theta .
\end{aligned}
$$

On the right-hand sides (14), (15), the factor $\frac{a}{r} \exp (i p r)$ is omitted, the left-hand sides are normalized by a factor $3\left[1+2(q / p)^{2}\right]^{-1}$, and displacements are attributed to $u_{0}$. The field of the incident wave and the corresponding field of the wave reflected from the boundary have the form: $u_{y}=u_{y}^{i}-u_{y}^{*}=\exp (i p y)-\exp [i(p y-2 p h)]$.

An approximate solution to the scattering problem in the second approximation is represented in the form

$$
u_{r} \cong U_{r 1}+U_{r 2} ; \quad u_{\theta} \cong U_{\theta 1}+U_{\theta 2} .
$$

The addition theorem for spherical wave functions is given in (Friedman \& Russek, 1954) [6]. 

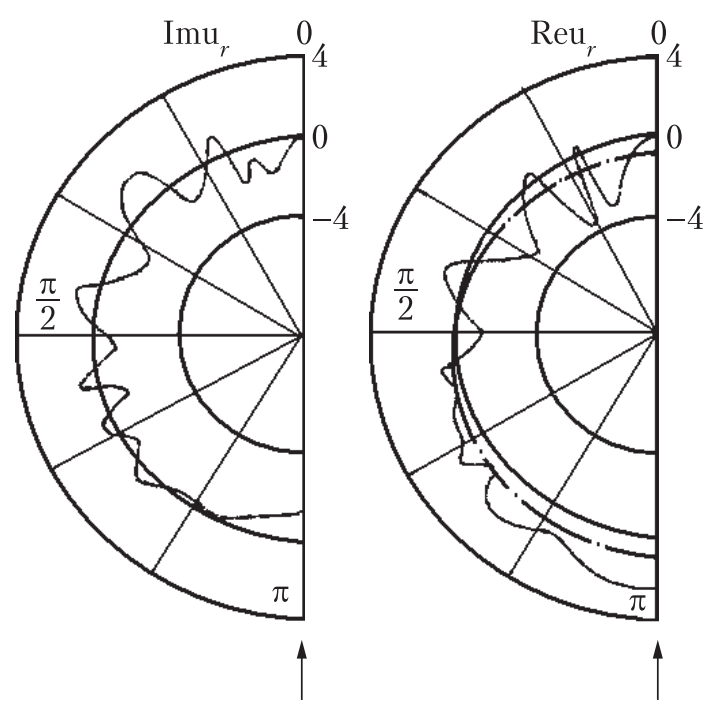

Fig. 1. Change in the values of the scattered field $\operatorname{Im} u_{r}$ and $\operatorname{Re} u_{r}$ at $h / a=20032$ (solid line) and at $h / r=\infty 76$ (dash-dotted line) without flat border.
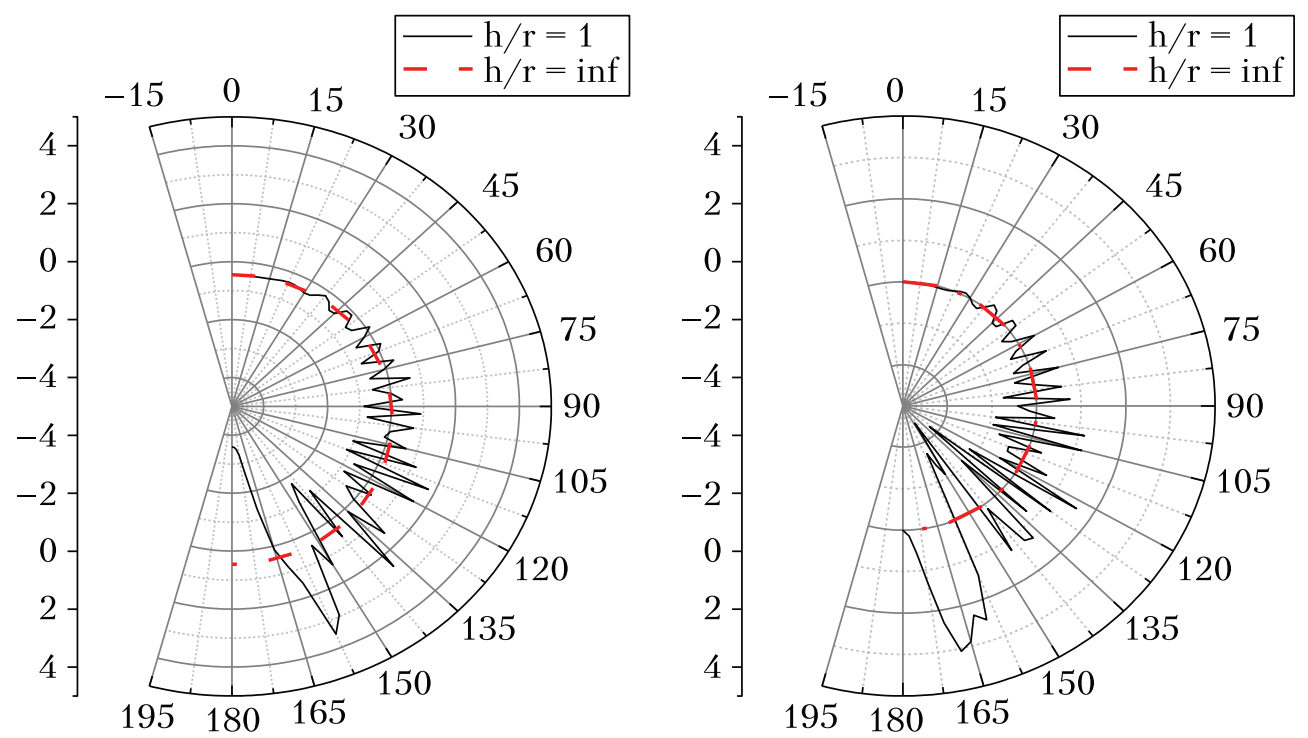

Fig. 2. Change in the values of the scattered field $\operatorname{Re} u_{r}$ и $\operatorname{Im} u_{r}$

As an example, let us find displacements $u_{r}$ and $u_{\theta}$ with the next data: Poisson's ratio $v=0.25 ; p a=0.8 ; r / a=200$. With the selected parameters, the error of the applied formulas does not exceed $10 \%$. Calculations are performed in points with a step of $\pi / 36$. The calculation results are shown in Fig. 1, where the oscillations of the re-reflected waves are clearly visible.

Below are the calculations and the scattering diagrams, which show a strongly oscillating wave field. The calculation results are obtained for the following parameters $p a=0.10, \frac{q}{p}=3.317$,
$h / a=200, r / a=200, p r=20, h / r=1, v=0.45$. 


\section{REFERENCES}

1. Selezov, I. T., Kryvonos, Yu. G. \& Gandzha, I. S. (2018). Wave propagation and diffraction. Mathematical methods and applications. Springer. In series Foundations of Engineering Mechanics, DOI 10.1007/978-98110-4923-1.

2. Selezov, I. T. (1993). Diffraction of waves by radially inhomogeneous inclusions. Physical Express, March. 1(2), pp. 104-115.

3. Morse, Ph. M. \& Feshbach, H. (1953). Methods of theoretical physics. Part I, New York. Mc Gray-Hill Book Company.

4. Seismic diffraction. (2016). SEG Geophysics reprint series N.30. Society of Exploration Geopgycists. 8801 S. Yale. Tulsa, USA.

5. Jackson, J. D. (1965). Classic electrodynamics. John Wiley \& Sons.

6. Friedman, B. \&Russek, J. (1954). Addition theorem for spherical waves. Quart. Appl. Math., 12, No. 1, pp. 13-23.

Received 03.07.2020

О.М. Хіміч ${ }^{1}$, I.T. Селезов $^{2}$, В.А. Сидорук ${ }^{1}$

${ }^{1}$ Інститут кібернетики ім. В.М. Глушкова НАН України, Київ

${ }^{2}$ Інститут гідромеханіки НАН України, Київ

E-mail:khimich505@gmail.com, igor.selezov@gmail.com,wolodymyr.sydoruk@gmail.com

ЧИСЕЛЬНЕ МОДЕЛЮВАННЯ ДИФРАКЦІЇ ПРУЖНИХ ХВИЛЬ НА СФЕРІ У НАПІВОБМЕЖЕНІЙ ОБЛАСТІ

Розглянуто проблему розсіювання плоских пружних хвиль твердою сферою, розташованою поблизу плоскої жорсткої межі, що призводить до породження багаторазово відбитих дилатаційних та зсувних хвиль. Постановка задачі дається, коли умови ковзання задаються на рівній межі (рівність нулю дотичних напружень). Проблема зводиться до визначення скалярних функцій. Записані загальні розв'язки і побудовані приблизні рішення для поля в дальній зоні, які характеризуються тим, що відстань від межі площини до перешкоди набагато більша за радіус кулі. Крім того, наближення Релея використовується, коли хвильове число набагато менше за радіус кулі. Метод зображень використовується для побудови множинно відбитих хвиль. Наведені приблизні формули поля в дальній зоні та у випадку довгохвильового наближення Релея. Проведені розрахунки розсіяних хвильових полів, представлені у вигляді діаграм розсіювання, з яких видно сильно коливальне хвильове поле.

Ключові слова: дифракція хвилі, пружні хвилі, сфера, напівобмежена область, метод зображення, коливальне поле, довжина хвилі. 